\title{
Companheirismo e sexualidade de casais na melhor idade: cuidando do casal idoso
}

The beauty of companionship and sexuality for couples in the best age: caring for elderly couple

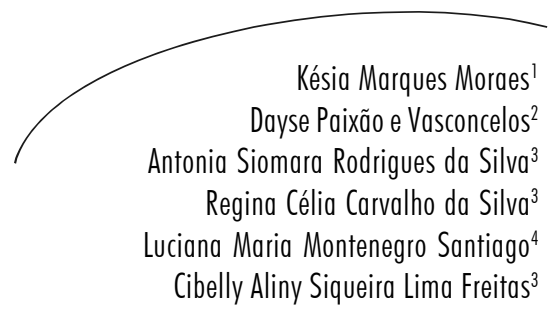

Resumo

Trata-se de um estudo de caso, com abordagem qualitativa, respaldado na Fenomenologia, que teve por objetivo compreender como o casal idoso vivencia a sexualidade, vislumbrando a busca de novas perspectivas de cuidar a partir da Teoria de Cuidado Transpessoal de Jean Watson. Participaram do estudo três casais idosos, pertencentes ao Grupo da Terceira Idade Envelhecendo com Alegria, do bairro Padre Palhano, município de Sobral/Ceará/Brasil. O estudo foi realizado no período de maio a julho de 2004, através de uma entrevista semiestruturada e aplicação do Teste das Oito Cores de Lüscher. Utilizou-se a análise de conteúdo proposta por Bardin. Diante da variedade de impressões obtidas na pesquisa, os resultados desvelam facetas importantes como a existência de sentimentos de amor, respeito, cumplicidade, mas também diminuição no padrão da atividade sexual, além do preconceito em relação à manifestação de carinho entre os gerontes e o fortalecimento do vínculo afetivo com o passar dos anos.

\section{Abstract}

It is a case study with a qualitative approach, supported in the Phenomenology, which aimed to understand how the elderly couple experience their sexuality, seeing the search for new perspectives of care from the Care Transpersonal Theory of Jean Watson. The study included three elderly couples, belonging to the Group of the Third Age Ageing with Joy, in Padre Palhano district, in the city of Sobral / Ceará / Brazil. The study was conducted from May to July 2004, through a semi-structured interview and application of the Test of Eight Colors of Lüscher. We used content analysis proposed by Bardin. Given the variety of

\footnotetext{
$\overline{1}$ Universidade Federal do Ceará. Departamento de Saúde Coletiva. Sobral, CE, Brasil.

2 Instituto Exitus. Curso Técnico de Enfermagem. Sobral, CE, Brasil.

3 Universidade Estadual Vale do Acaraú - UVA. Curso de Enfermagem. Departamento Centro de Ciências da Saúde. Sobral, CE, Brasil.

4 Centro de Educação Tecnológico - CENTEC. Escola Estadual de Ensino Profissionalizante Dom Walfrido Teixeira Vieira. Sobral, CE, Brasil.
}

Palavras-chave: Idoso. Sexualidade. Cuidados de enfermagem.

Comportamento Sexual. Afeição. 
impressions gained in the research, the results disclose important facets such as the existence of feelings of love, respect, complicity, but also a decrease in the pattern of sexual activity, and prejudice in relation to expressions of affection between gerontes and strengthening of bonding over the years..
Key words: Elderly. Sexuality. Nursing care. Sexual Behavior. Affect.

\section{INTRODUÇÃO}

A assistência ao idoso vem evoluindo significativamente nas últimas décadas, principalmente devido ao aumento da expectativa de vida da população e diminuição da taxa de natalidade, o que proporcionou um aumento no número de idosos na população brasileira.

No decorrer das últimas décadas, a enfermagem despertou para o cuidado ao idoso, merecendo destaque o crescimento da enfermagem gerontológica, que tem possibilitado capacitação para o atendimento às expectativas $\mathrm{e}$ necessidades relacionadas com a terceira idade. ${ }^{1}$ Torna-se imperativo que o enfermeiro compreenda o idoso nos seus aspectos físicos, psíquicos e sociais, prestando, assim, uma assistência adequada. Também é indispensável que o profissional tenha conhecimento científico para discernir as alterações anatômicas e funcionais naturais do envelhecimento, das patológicas.

Junto às rugas na pele e aos cabelos brancos chegam múltiplos desafios, como as alterações fisiológicas, que tornam o organismo mais susceptível às doenças e às alterações psicológicas, que podem demandar o medo, a depressão e o isolamento social. Esse quadro geralmente dificulta a aceitação do envelhecimento e ainda é agravado pelos mitos e estereótipos relacionados à velhice.

Entre os mitos e estereótipos encontra-se o de que o idoso não mais vivencia sua sexualidade, como se o envelhecimento carregasse consigo o desinteresse pela vida e a sexualidade fosse inerente ao jovem. É importante notar que a sexualidade não se resume ao coito, com a única finalidade de procriação, ela vai muito mais além, trata-se de um misto de prazer, comunicação e amor entre duas pessoas como uma forma de conhecimento do seu corpo e do corpo do outro, fortificando os laços de união de um casal. Existem outras formas do idoso vivenciar sua sexualidade, como um longo abraço, um beijo carinhoso e carícias. Estes são comportamentos que estão intimamente relacionados com a sexualidade; a intimidade e demonstração de ternura pela pessoa amada; a sensualidade presente nas várias formas de comunicação; um toque de carinho nas mãos, no rosto de quem se gosta; tocar seu corpo e descobrir que ainda existe prazer para ser explorado. ${ }^{2}$

A sexualidade é parte integrante da personalidade do ser humano. Seu desenvolvimento se completa com a satisfação das necessidades humanas básicas, como o desejo de contato, intimidade, expressão emocional, prazer, amor e carinho. ${ }^{3}$

O interesse em estudar o universo que envolve a terceira idade veio da participação no Projeto de Extensão intitulado: A Enfermagem como arte/ciência no cuidar de idosos, onde podemos conhecer um pouco do vasto mundo dessa clientela. As atividades estavam ligadas à assistência de enfermagem prestada a idosos de comunidades carentes, assistidos pelo Programa Saúde da Família (PSF).

Observando essa vontade de viver dos idosos $\mathrm{da}$ comunidade, vieram alguns questionamentos, tais como: $\mathrm{O}$ que eles consideram sexualidade?; Como eles vivenciam sua sexualidade, visto que na velhice a libido e a atividade sexual diminuem, mas não desaparecem?; Existe manifestação de carinho nesses casais idosos?; O que mudou em relação à sexualidade no decorrer do tempo de união do casal na terceira idade?.

Diante desse contexto, veio o desejo de oferecer suporte e apoio a estes idosos, durante o processo de envelhecimento para lidarem com as alterações sexuais e vivenciarem a sexualidade plenamente, de modo que essa vivência saudável contribua para melhorar a qualidade de vida do 
casal idoso, visto que a enfermagem tem um importante papel nesse sentido.

A Enfermagem é uma ciência humanística, que trata do cuidado de pessoas e de experiências no campo dos conhecimentos específicos, fundamentações e práticas do cuidar dos seres humanos que abrangem tanto o estado de saúde quanto os estados de doença, mediada por transações pessoais, profissionais, científicas, estéticas, éticas e políticas. ${ }^{4}$

A enfermagem tem utilizado o conhecimento emprestado de outras disciplinas, principalmente das ciências naturais e sociais, para guiar o desenvolvimento e a prática de enfermagem. ${ }^{5} \mathrm{~A}$ utilização de teorias emprestadas de outras ciências dá suporte aos blocos construtores, aos conceitos derivados de outras teorias, favorecendo o desenvolvimento das teorias de enfermagem, de psicologia humanística, existencial e transpessoal. Entendendo a sexualidade como um fenômeno na vida do ser humano, optou-se pela Teoria do Cuidado Transpessoal de Jean Watson.

Espera-se desse estudo um caminho para aproximar ainda mais a enfermagem do seu papel social, promovendo a saúde sexual no processo de envelhecimento da melhor forma possível.

O objetivo do estudo foi buscar compreender sobre como o casal idoso vivencia a sexualidade, a fim de vislumbrar novas perspectivas de cuidar, a partir da Teoria do Cuidado Transpessoal de Jean Watson.

\section{MÉTODOS}

A presente pesquisa constitui-se de um estudo de caso com abordagem qualitativa, por se tratar de um estudo em profundidade, exaustivo, radical, de uns poucos objetos, visando obter o máximo de informações que permitam o amplo conhecimento, o que seria impossível em outro tipo de pesquisa. ${ }^{6}$

O estudo está respaldado na Fenomenologia, através da Teoria do Cuidado Transpessoal de Jean Watson, que afirma que nessa corrente, a verdade é aquela experimentada e vivida existencialmente pelo sujeito que a informa e assume o fenômeno como algo que aparece à consciência, ou seja, se mostra ao pesquisador, o qual só pode ver o que aparece. Nela, o objetivo precípuo é a investigação direta e a descrição de fenômenos que são experienciados conscientemente, sem teorias para sua explicação causal, e tão livre quanto possível de pressupostos e de preconceitos.?

Portanto a fenomenologia é uma descrição da estrutura específica do fenômeno, sendo que sua análise vai muito além da simples análise psicológica, pois o método fenomenológico não procura as condições sob as quais o juízo é verdadeiro e sim qual o significado daquilo que se passa na consciência, quando alguém julga, sonha, afirma, vive. ${ }^{7}$ Devem-se descrever os fenômenos tais como se manifestam, como dados puros e simples da consciência, como significados. Sua tarefa fundamental consiste em torná-los visíveis e aparentes como tais.

A enfermagem tem como destaque na sua prática cotidiana o cuidar. Diante desse contexto, foi proposta durante o desenvolvimento do estudo, a apreciação e aplicação da Teoria de Cuidado Transpessoal de Jean Watson, baseada em pressupostos fenomenológicos existenciais, procurando compreender as pessoas a partir de suas estruturas de referência, levando especialmente em consideração sua percepção dos fenômenos. ${ }^{8}$

Watson propõe uma filosofia, ciência e arte de Enfermagem onde as idéias e ideais associados, formam a teoria do cuidado humano. Seu trabalho é baseado no desenvolvimento mental-espiritual do EU e do OUTRO, como também à descoberta da força interior e autocontrole através do cuidado, tudo isto proporcionado pela interação inter-transpessoal. Esta transação de cuidado humano não vem sendo feita de forma articulada, nutrida ou reconhecida como fundamental, para o processo de cuidar profissional, porque para Watson, a enfermagem tem focalizado sua atuação muito voltada à matéria e à forma. ${ }^{9}$ 
O conhecimento concebido por Watson é considerado uma filosofia de enfermagem, pois sua obra parte de uma perspectiva fenomenológica-existencial. É a única teoria de enfermagem a defender explicitamente o conceito de alma e enfatizar a dimensão espiritual da existência humana. ${ }^{10}$

\section{Os fatores carativos são: ${ }^{10}$}

1. Formação de um sistema de valores humanista-altruísta - engloba os valores do indivíduo a partir dos valores preconizados pelos pais ao longo da vida, sendo mediado através das próprias experiências pessoais.

2. Promoção de fé-esperança - é destacado como um fator essencial para os processos de cuidado e curativos. Destaca o espiritual, a alma e o espírito, com o intuito de buscar um sentido existencial e transcendental, na visão que vai além da ciência moderna.

3. Cultivo da sensibilidade ao próprio self e aos outros - explora o desenvolvimento dos próprios sentimentos que alguém pode, realmente, de modo sensível, interagir com os outros. A mente e as emoções de uma pessoa são janelas para a alma.

4. Estabelecimento de uma relação de ajudaconfiança-abrange um modo de comunicação que estabelece harmonia e cuidado, caracterizados pela compatibilidade, empatia e calidez, havendo nas interações verdade, honestidade, abertura, sintonia e aceitação positiva do outro.

5. Promoção e aceitação de sentimentos positivos e negativos - os sentimentos alteram os pensamentos e o comportamento, e precisam ser considerados e permitidos em uma relação de cuidado, visto que interferem na saúde física e psicológica.

6. Utilização sistemática do método científico para resolução de problemas - visa monitorar, prever e conduzir o cuidado, imprimindo ao mesmo um enfoque científico.

7. Promoção do ensino-aprendizagem interpessoal-proporciona às pessoas o máximo de controle sobre sua própria saúde, oferecendolhe informações e alternativas. $\mathrm{O}$ processo de aprendizagem e ensino é focalizado, uma vez que a aprendizagem propicia o melhor caminho de individualização da informação a ser disseminada.

8. Provisão de um ambiente de apoio, proteção e/ou de neutralização mental, física, sociocultural e espiritual - $\mathrm{o}$ ambiente do cliente inclui variáveis externas e internas interdependentes, que podem ajudar o indivíduo a enfrentar alterações, na busca de desenvolver uma percepção mais exata e oferecer informações cognitivas que reforcem mecanismos de enfrentamento.

9. Assistência das necessidades humanas as necessidades humanas são consideradas por Watson hierarquicamente, abrangendo desde necessidades de ordem inferior, superior ou de busca de crescimento. Todas as necessidades devem ser valorizadas e cada uma deve ser entendida dentro do conjunto das demais.

10. Permissão de fatores existenciaisfenomenológicos - este fator sugere um voltarse para o próprio interior, encarando as próprias indagações existenciais, antes de conseguir ajudar a outras pessoas a enfrentar a difícil situação humana.

A pesquisa foi realizada no bairro Padre Palhano, localizado na periferia do município de Sobral/CE/Brasil. No bairro, a população é de 8.487 habitantes, onde a maioria das pessoas em idade produtiva está desempregada ou subempregada, recebendo um ou menos de um salário mínimo. O Centro de Saúde da Família (CSF) do bairro - Unidade de Saúde Herbert de Sousa atende a 1.740 famílias, divididas em oito micro-áreas, prestando assistência à saúde as mesmas. $^{11}$

O município de Sobral, onde está localizado o bairro Padre Palhano, está situado no sertão Centro-Norte do Ceará, a $224 \mathrm{~km}$ de Fortaleza, capital do Estado. Sua população é predominantemente jovem, com $50 \%$ dos sobralenses concentrados na faixa etária de $\mathrm{O}$ a 
17 anos, 20\% entre os 7 e 14 anos. Porém, o acentuado crescimento da população idosa é fato no município de Sobral, com 13\% da população composta de pessoas de 50 anos ou mais. $^{2}$

Considerando os objetivos do estudo, foram convidados cinco casais integrantes do grupo de idosos promovido pelo Centro de Saúde do referido bairro para participar da pesquisa, no entanto somente três casais aceitaram participar do estudo.

A coleta de dados foi realizada no período de maio a julho de 2004, através da participação ativa no Grupo da Terceira Idade Envelhecendo com Alegria e de visitas domiciliárias aos casais idosos.

Para coleta de dados, utilizou-se como instrumento uma entrevista semi-estruturada e a aplicação do Teste das Oito Cores de Lüscher, através do qual foram registradas informações psicológicas a respeito dos sujeitos estudados, mediante suas preferências e rejeições às cores.

Aplicou-se o Teste das Oito Cores de Lüscher, criado por Haack, ${ }^{12}$ considerado um teste simples, essencialmente não-verbal, que pode ser aplicado e interpretado com rapidez, esteticamente agradável e dá um vislumbre revelador da estrutura da personalidade.

O Painel de Oito Cores é dividido em quatro cores básicas ou "primárias psicológicas", que compreendem o azul, verde, vermelho, amarelo e quatro cores auxiliares representadas pelas cores violeta, marrom, preto e cinza.

No Teste Integral de Lüscher há sete painéis diferentes de cores, contendo todos os setenta e três borrões coloridos, que consistem de vinte e cinco matizes e tonalidades diversas, e exigindo que se façam quarenta e três escolhas diferentes. $\mathrm{O}$ protocolo do teste resultante oferece um tesouro de informações sobre a estrutura psicológica consciente e inconsciente da pessoa, áreas de tensão psíquica, o estado de equilíbrio glandular e muitas outras informações fisiológicas de grande valor para o profissional que executa o teste. ${ }^{12}$
No entanto, para o nosso estudo, utilizamos a versão resumida do teste, conhecida como Teste Rápido ou Teste Abreviado de Lüscher, que apresenta considerável poder para salientar os aspectos importantes da personalidade e para chamar a atenção para as áreas de tensão psicológica e fisiológica onde elas existam.

No teste, a pessoa que está sendo submetida a ele (ou aplicando a si própria), escolhe as cores em ordem decrescente de preferência; a cor que ela prefere e coloca na primeira posição é, assim, aquela pela qual tem a maior simpatia; a que ela escolhe por último e coloca na oitava posição é aquela pela qual tem mais rejeição ou menor simpatia.

Uma vez interpretado o Teste das Oito Cores de Lüscher, o seu resultado compôs um padrão individual, o qual foi posteriormente, submetido à análise de conteúdo proposto por Bardin, tendo em vista os objetivos propostos para o estudo.

Para organizar os dados, estabeleceu-se o uso da Técnica de Análise Categorial. As categorias referem-se a um conceito que abrange elementos ou aspectos com características comuns ou que se relacionam entre si; são estabelecidas para classificar os eventos. Categorizar é agrupar elementos, idéias ou expressões em torno de um conceito capaz de representá-los. ${ }^{13}$

Finalizando a etapa da organização dos achados, partimos para o processo de análise, compreendendo, portanto, a descrição fiel de todos os encontros semanais e visitas domiciliárias, interpretação das informações obtidas através do Teste das Oito Cores de Lüscher, emprego de alguns dos fatores carativos e o uso de quatro categorias abstraídas a partir dos discursos dos gerontes. ${ }^{14}$

O estudo foi submetido à apreciação do Comitê de Ética em Pesquisa da Universidade Estadual Vale do Acaraú - UVA, e aprovado conforme Protocolo 153. Os participantes assinaram um Termo de Consentimento Livre e Esclarecido. Foram obedecidos aos princípios estabelecidos pela Resolução 196/96, do Conselho Nacional de Saúde, que trata de pesquisa 
envolvendo seres humanos. ${ }^{15}$ Aos casais participantes foram atribuídos nomes de personagens da mitologia grega (Dioniso e Ariadne, Hades e Perséfone, Eros e Psique), com $\mathrm{o}$ intuito de preservar o anonimato.

\section{RESULTADOS}

Nesta etapa, cada casal foi caracterizado, e em seguida, foi apresentada uma síntese do resultado do Teste das Oito Cores de Lüscher. Finalmente, discorreram-se as informações obtidas acerca dos questionamentos sobre sexualidade organizada em categorias, abstraída a partir de seus discursos.

Nove foram os encontros semanais vivenciados no período de maio a julho de 2004. Concomitante aos encontros semanais foi realizada visitas domiciliárias aos casais do grupo, por serem estes os atores sociais do estudo.

\section{Conhecendo os casais idosos}

\section{0 grande e compreensivo amor de Dioniso e Ariadne}

Ariadne tem 64 anos, estudou até a primeira série do ensino fundamental, é católica, ajudou o marido no roçado, mas hoje é dona-de-casa. Participa do grupo assiduamente há quatro anos.

Dioniso tem 66 anos, estudou até a segunda série do ensino fundamental, é católico, trabalhou como agricultor, métre no Rio de Janeiro e hoje é vigilante de um CSF no município de Sobral/ CE. É aposentado, agricultor e nas horas vagas exerce a função de fotógrafo. Participa do grupo esporadicamente há três anos.

O casal mora em casa própria com uma filha e duas netas e são casados há 44 anos e têm oito filhos.

No início da coleta de dados, achávamos que Dioniso não queria participar do estudo, pois sempre que chegávamos à sua casa, tinha algo a fazer. Após várias tentativas conseguimos falar com ele.
Dioniso se considera um homem sadio e realizado. É muito vaidoso. Morou muito tempo nos Estados do Rio de Janeiro e São Paulo. No Rio de Janeiro trabalhou em restaurantes. Passou um mês "lavando pratos", até que passou a ser cozinheiro e depois métrenum restaurante em Copacabana. Disse que conheceu várias pessoas famosas e até recebeu convites para morar na França e Espanha. Seus olhos brilhavam ao falar de suas lembranças, mas seu sonho era voltar pro seio da família.

A esse casal foi realizada quatro visitas domiciliárias, sendo que o Teste das Cores foi realizado separadamente. $\mathrm{Na}$ primeira visita realizamos o teste com Ariadne que mostrou muita curiosidade a respeito da "brincadeira", esclarecemos que era um teste psicológico que fazia parte da pesquisa. Ela mostrou preferência pela cor verde. Com Dioniso o teste foi realizado na terceira visita, ele ficou confuso para escolher as cores e não mostrou muita curiosidade em relação ao método.

Em alguns momentos percebeu-se a timidez de Ariadne diante dos questionamentos sobre sexualidade. Ela relaciona a diminuição da libido à cirurgia realizada (histerectomia). Foi esclarecido que não havia essa relação, que o desejo está no íntimo de cada pessoa, independente do procedimento cirúrgico o qual a pessoa for submetida. Porém, Dioniso se sentiu muito a vontade e expressou quando falamos de carinho, pois é muito carinhoso e Ariadne não lhe retribui com a mesma intensidade. Foi observado também o respeito à privacidade deles, visto que os questionamentos foram realizados separadamente sem que nós solicitássemos.

\section{O amor fraterno de Hades e Perséfone}

Perséfone tem 64 anos, só estudou a alfabetização, é católica e hoje é dona-de-casa, mas já foi agricultora.

Hades tem 64 anos, só assina o nome, é católico, foi agricultor e pedreiro, hoje é vigilante de um CSF neste município.

O casal teve quatro filhos, mora em casa própria com um filho e uma neta e são casados há 43 anos. 
O Teste das Cores foi realizado com Hades na segunda visita domiciliária, ele disse que não via muita diferença entre as cores e que as pessoas são muito inteligentes por descobrirem como os outros são através de cartões coloridos. Mostrou preferência pelo amarelo. $\mathrm{O}$ teste com Perséfone foi feito na terceira visita, ela não demonstrou preferência por nenhuma cor específica.

Hades falou que adora "estar em sociedade", ou seja, gosta de participar de todos os eventos do seu bairro. É fiscal da Unidade Produtiva São Paulo e do Conselho Local de Saúde (CLS). Foi fiscal da delegacia do bairro (Conselho Local de Segurança), mas devido às doenças que tem, não se compromete mais com muita coisa. Moram no bairro há 14 anos e ele sempre procura participar de todos os eventos da comunidade. Faz muitos planos para o futuro, tanto que mostrou um terreno ao lado de sua casa, onde pretende construir outra.

Assim como aconteceu com o primeiro casal, foram realizados os questionamentos individualmente para que eles ficassem mais a vontade. Perséfone tem uma dedicação única para com Hades e eles vivem o amor de uma forma fraternal, simples, porém, verdadeira.

\section{0 afeto duradouro de Eros e Psique}

Psique tem 66 anos, é analfabeta, católica, aposentada e já foi agricultora. Participa do grupo há seis anos, há mais tempo que seu esposo.

Eros tem 72 anos, é analfabeto, católico, aposentado, vende carvão e já foi agricultor. Participa do grupo há cinco anos, mas às vezes tem vontade de sair do grupo porque praticamente só tem mulher. Ele é o homem mais assíduo, mas quando pensa que se não for para o grupo vai ficar em casa sem fazer nada, desiste da idéia. Disse também que adora dançar, apesar da perna "defeituosa”, conseqüência do reumatismo.

Eles moram com dois filhos em casa própria, tiveram 13 filhos, mas somente nove são vivos. São casados há 49 anos.
Diferente dos outros casais, o Teste das Cores foi realizado na primeira visita domiciliária e com os dois.Foi percebida a forma carinhosa como eles se tratavam: nego e nega. Primeiro fiz com Psique, que adorou todas as cores. Eros perguntou para que serviam aquelas cartas coloridas. Foi esclarecido que era um teste psicológico que mostrava como a pessoa era a partir da escolha das cores. Então, ele fez sua seqüência de cores, demonstrando preferência pelo verde e aversão ao marrom.

A presença de muitas pessoas dentro da casa atrapalhou o desenrolar da entrevista, visto que Eros é muito introvertido. Evitou-se tocar no assunto do estudo, aos poucos eles foram saindo da sala, até que nos deixaram a sós com o casal e uma neta deles, para que assim pudéssemos iniciar os questionamentos.

Realizou-se uma nova visita ao casal e mais uma vez a casa estava cheia. Conversamos pouco. Ao retornar ao domicílio do casal para agradecer pela contribuição no estudo, eles nos abraçaram e se dispuseram a ajudar no que fosse necessário.

\section{A vida e a sexualidade na Terceira Idade}

Retrataram-se em forma de categorias as respostas abstraídas a partir dos questionamentos relacionados à sexualidade dos casais idosos.

\section{O significado da sexualidade para quem vivencia a Terceira Idade}

A primeira categoria enfoca a percepção do idoso sobre sua própria sexualidade. As pessoas entrevistadas demonstraram em seus discursos diferentes maneiras de compreender a sexualidade. A percepção de sentimentos é revelada, quando alguns dos entrevistados a definem como amor, respeito, compreensão, amizade e união. Pode-se confirmar o exposto através de suas falas:

"Eu nem sei... É amor, amizade, querer bem. Muitas pessoas dizem que para ser feliz no casamento tem que ter sexo. A gente tem uma relação sexual por semana, masporque ele quer. Homemé homem. Parece que quando a gente vai ficando velha, o fogo se apaga. 
Eu não gosto muito não, faço mais porque ele quer." (Ariadne)

"Eu nem sei bem o que é isso, eu não sei não... é muito bom. A união do casal e a paz dentro de casa é muito bom. Somos unidos, mas nos desentendemos porque ele é muito teimoso. Deve ser de tanto remédio que ele toma." (Perséfone)

"Não sei lhe dizer. Não seifalar direito. Sexualidade pra mim é respeito e amor." (Eros)

Ariadne, Perséfone e Eros tiveram dificuldade para expressarem-se ao serem abordados sobre a temática. Pode-se observar nos relatos a diversidade de definições para sexualidade nos gerontes entrevistados. $\mathrm{O}$ aparecimento $\mathrm{da}$ sexualidade nos humanos faz aparecer o amor como relação de liberdade, gratuidade e mútua doação entre os parceiros. A sexualidade-amor é a força mais poderosa de modelagem das existências e de geração de sentido para a vida que historicamente conhecemos. ${ }^{16}$

Entretanto, verificou-se o estigma que o idoso carrega da sociedade em não viver sua sexualidade plenamente nesse período da vida na fala de Ariadne. O Teste das Cores confirma o comportamento de Ariadne, visto que em um dos resultados do teste é enfocado que ela está sob considerável tensão devido às exigências $\mathrm{da}$ situação presente.

Durante a terceira idade a frequência dos episódios de desejo se torna mais espaçada, independentemente do parceiro. Portanto, os homens têm uma mudança de padrão de resposta sexual, mas para quem vive essas mudanças, o sexo continua sendo tão satisfatório quanto era na adolescência. Para as mulheres também o sexo é tão prazeroso quanto era na juventude, embora a excitação seja mais lenta e o orgasmo possa ser acompanhado de um desconforto. ${ }^{17,18}$

$\mathrm{Na}$ sociedade brasileira, a definição de sexualidade feminina é, ainda, tradicionalmente referida à condição biológica e associada à esfera familiar da reprodução e, portanto, à maternidade; a da sexualidade masculina tem sua identidade assentada nas atividades da esfera pública, concentradora dos valores culturais e materiais, o que faz do homem o provedor e o protetor da família, legitimada, pois, no binômio reprodutor-trabalho. ${ }^{18}$

Os fatores de cuidado 1 e 5 falam sobre valores da pessoa a partir dos valores ensinados pelos pais ao longo da vida de cada ser, pois estão associados à formação de um sistema de valores humanistaaltruísta, e a promoção e aceitação de sentimentos positivos e negativos, que enfoca que os sentimentos necessitam ser considerados e permitidos em relação de cuidado. ${ }^{14}$

\section{Mudanças ocorridas na união dos casais na Terceira Idade}

Quando indagadas acerca das mudanças ocorridas na união dos casais na terceira idade, percebeu-se que alguns casais, como Perséfone e Eros apontaram a existência de mudanças na relação conjugal com o passar dos anos, principalmente na esfera sexual.

Além disso, percebeu-se a presença de significados diferentes sobre a atividade sexual entre o gênero masculino e feminino, conforme as falas.
"Não mudou muito não. O que mudoné que ele era muito de brincadeira, gostava de sair pra beber. Que en saiba, ele nunca teve outra mulher. Não namoramos mais. Acho que é por causa de tanta doença que [Hades] tem. Ele não tem mais sensação, mas ainda tem vontade. Acho que se ele fosse bom de saúde ele era como um bomem normal. Não sinto falta, nunca gostei dessas coisas. Quando a gente era novo era tudo diferente. Masébom porque eu não tenho vontade e ele não pode. Jápensou se fosse um quente e o outro frio? Não ia dar certo (risos)" (Perséfone)
"Se eu falar que não mudou vou estar mentindo. Não gosto de contar vantagem. Quando se é mais novo tudo é mais e quando passa a ser velho, tudo diminui. Diminui a força... ofolego... a coragem, tudo, você entendeu né? Bastava eu chegar perto que ela não negava. Hoje é diferente."(Eros)

Podemos identificar uma visão diferente para a sexualidade no discurso de Dioniso, onde ele menciona que a sexualidade não é somente $\mathrm{o}$ ato 
sexual, fazendo uma relação entre fidelidade e traição.

"A coisa mais importante na minha vida é a [Ariadne]. Sexualidade não é só sexo, é amor, respeito e compreensão. Posso até já ter tido outras, mas nunca mulher nenhuma vai tomar o lugar dela. Ela é a pessoa que eu mais adoro no mundo." (Dioniso)

As reminiscências estão presentes em alguns discursos, onde os entrevistados fazem uma comparação do passado com o presente. $\mathrm{Na}$ fala de Dioniso verificou-se que este aponta a diminuição do desejo sexual de Ariadne como uma mudança significativa no relacionamento do casal.

Acima dos 65 anos, diminui no homem a capacidade de desenvolver uma ereção total do pênis, o tempo necessário para a ejaculação e a quantidade de sêmen ejaculado. Nas mulheres podem ocorrer algumas modificações no trato urogenital após a menopausa. ${ }^{19}$

As transformações fisiológicas citadas acima, implicam, também, em transformações na beleza e na forma do corpo. Há também um marcante declínio na atividade sexual entre os idosos. Enquanto a maioria dos casais entre 60 e 74 anos é sexualmente ativa, apenas um quarto daqueles com mais de 75 anos relatam o coito conjugal. Ocorre alguma masturbação, particularmente entre os viúvos. As mudanças nas taxas de atividade refletem tanto fatores psicológicos como mudanças fisiológicas definitivas. ${ }^{19}$

$\mathrm{Na}$ velhice, há maior predisposição às doenças e à incapacidade. As doenças mais freqüentes são as cardiovasculares e os distúrbios que comprometem o aparelho musculoesquelético. Uma enfermidade ou doença pode incapacitar um dos parceiros sexuais. Geralmente o homem desenvolve moléstias mais graves primeiro, deixando a mulher sem parceiro sexual. ${ }^{20}$

Se um dos parceiros adoece, o outro reage com preocupação, mas se a doença torna-se crônica, o parceiro saudável pode se surpreender ao perceber que está irritado com o doente. Isso é um reflexo do medo de perder o parceiro; também pode ser a exaustão por trabalho ou um ressentimento por perder coisas divertidas. ${ }^{21}$

Hades e Psique não apontaram muitas mudanças, o tempo consolidou a união do casal e a amizade predominou no relacionamento. Isto é notável em seus depoimentos:

"Ficamos mais amigos. Não mudou muita coisa não. A gente não briga, é unido. A gente não tem mais nada."(Hades)

"Não mudou muito nada não. A gente continua carinhoso do mesmo jeito."(Psique)

Os achados do Teste das Cores corroboram a resposta de Hades, onde diz que ele precisa de uma vida pessoal de compreensão mútua e de estar livre de discórdia. O mesmo ocorre com Psique, onde o teste diz que esta é uma pessoa dócil, adaptável e tem altas exigências emocionais.

Diante dessa situação, comprovou-se que o fator de cuidado 4 é de suma importância, pois estabelecemos uma relação de ajuda-confiança, gerando harmonia e cuidado. ${ }^{14}$

O sucesso conjugal na velhice está ligado à intimidade, à companhia e à capacidade de expressar sentimentos verdadeiros um para o outro, numa atmosfera de segurança, carinho e reciprocidade. A continuidade da atividade sexual na terceira idade está ligada à intimidade, sendo improvável que uma ocorra sem a outra. ${ }^{21}$

Diante dessa categoria, pensou-se na importância do fator de cuidado 3 que fala do cultivo da sensibilidade ao próprio selfe ao das demais pessoas. Esse fator explora o desenvolvimento dos próprios sentimentos que alguém pode interagir com os outros de modo

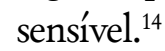

\section{Vivência da sexualidade pelos casais idosos}

Ao serem questionados a respeito da vivência da sexualidade do casal, verificou-se que Dioniso, Hades, Perséfone, Psique e Eros deram ênfase nas suas respostas às relações sexuais. 
"Nós temos de duas a três relações sexuais por semana, mas ela nãogosta muito. Ela nuncafoi uma mulber quente, de me chamar, de me procurar, sempre son en e ela não nega. Ela às vezes reclama do men jeito. Nunca brigamos, játivemos divergências, mas ela sempre tinha razão. Nunca passamos um dia sem sefalar."(Dioniso)

"Era um homem completo, mas não tenho mais aquele gás. Minha mulher nunca foi uma mulber quente. Quando era novo tinha muito gás e ela sempre me satisfazia, mas hoje por causa de tanta doença ébem diferente. Não tenho mais relação, tenho sensação, vontade, mas não faço mais não. Não tenho...como chama?... o santo não ajuda mais a subir (risos) Tem 14 anos que sou doente e faz 10 anos que não tem mais sexo entre a gente. Ela sofreu muito nos partos. Resolvipoupar ela. Não sou chateado por isso, tudo é da natureza de Deus e eu consigo viver sem isso. Para um homem que toma 20 comprimidos por dia é muito difícil."(Hades)

"A gente vive muito unido, não briga, um escuta o outro. Dormimos na mesma cama, mas não acontece nada, nem abraço." (Perséfone)

"Não entendi a pergunta...(risos) Vixe minha filha, é muito diferente (risos). Às vezes ele vem aí eu invento uma dor na perna pra não continuar e ele acaba desistindo e dorme."(Psique)

"Antes era muito bom. Temos duas, três ou quatro relações...por mês, eu não agüento mais não (risos) Mesmo sem sexo vivemos o nosso amor, nunca brigamos."(Eros)

"Nós conversamos muito, somos unidos. O amor e o bem quereré o mesmo."(Ariadne)

O teste das cores valida as afirmações de Eros, onde afirma que aquele é sensível, necessita de ambientes estéticos ou de cônjuge igualmente sensível e compreensivo, com quem possa compartilhar de uma intimidade aconchegante. O mesmo acontece com Dioniso, onde o teste revela que ele é capaz de sentir satisfação física na atividade sexual, mas tende a manter-se emocionalmente distante.

Muito do que a pessoa experimenta durante o envelhecimento é marcado por regras sociais nem sempre atualizadas ou satisfatórias, que a impedem de realizar aquilo de que é capaz. Algumas são tão disseminadas que são difíceis de esquecer, e muitos idosos terminam por aceitálas e comportam-se de acordo com o esperado. ${ }^{20}$

A aceitação do fato que há vida sexual ativa nos anos finais da vida é muito recente. Durante muito tempo admitiu-se que, com o correr dos anos, a vida sexual era praticamente impossível, talvez imoral e inquestionavelmente absurda. ${ }^{22}$

As mulheres são mais centradas na teia das relações pessoais, entregues ao cuidado da vida. Nas relações sexuais, a mulher procura antes a fusão que o prazer, mais o carinho que o intercurso sexual. Na sua grande maioria precisa amar para fazer sexo, por não dissociar amor de sexo. O homem, por sua vez, dissocia facilmente amor de sexo, busca antes o prazer que o encontro profundo. ${ }^{16}$

A sexualidade não tem o mesmo grau de importância para todos os sujeitos. Mais do que um recurso explicativo baseado em diferenças psicológicas, essa variação é efeito de processos sociais que se originam no valor que a sexualidade ocupa em determinados nichos sociais e nos roteiros específicos de socialização com que as pessoas se deparam. ${ }^{23}$

Destacou-se que o fator de cuidado número 3 com o cultivo da sensibilidade ao próprio selfe aos outros que explora a necessidade de a enfermeira começar a sentir uma emoção, quando ela se faz presente e quando as enfermeiras lutam para aumentar sua própria sensibilidade, elas se tornam mais autênticas. Essa categoria se encaixa no fator de cuidado 7, que exalta a promoção do ensino-aprendizagem, proporcionando às pessoas o máximo de controle sobre sua própria saúde, já que elas próprias oferecem informações e alternativas. ${ }^{14}$

\section{DISCUSSÃO}

A concretização deste estudo nos possibilitou buscar compreender sobre como o casal idoso vivencia a sexualidade, a fim de vislumbrar novas 
perspectivas de cuidar, a partir da Teoria do Cuidado Transpessoal de Jean Watson.

Notamos uma heterogeneidade de respostas às indagações relacionadas à compreensão da sexualidade, que foi revelada através de sentimentos como amor, respeito, carinho, união, amizade ou algo que vai além do ato sexual.

Nessa pesquisa, constatou-se ao falar das mudanças ocorridas na união dos casais na terceira idade uma comparação do passado em relação ao presente. Foram enfocados o vínculo afetivo, que se fortaleceu com o passar dos anos e a continuidade da atividade sexual.

Observou-se, no decorrer do estudo, ao serem questionados sobre a vivência da sexualidade, que a maioria mencionou a diminuição no padrão da atividade sexual devido à idade, patologias, uso de medicamentos ou mesmo à diminuição do desejo, embora também tenha se manifestado a permanência do amor e da união em uma relação duradoura mesmo com a ausência do ato sexual.

Detectou-se que a manifestação de carinho permaneceu na maioria dos entrevistados, apesar de alguns não exercerem a atividade sexual por considerarem que isso é impróprio para eles.

A relevância desta pesquisa mostra-se à medida que desvela as mudanças que ocorrem na sexualidade no mundo dos idosos. É importante que os profissionais de saúde possam cuidar dos idosos, considerando as questões relacionadas à sexualidade.

Dessa forma, teremos profissionais de saúde sensibilizados com a assistência à saúde sexual do casal idoso, o que possibilitará uma prática de cuidados livre de julgamentos e preconceitos.

\section{CONCLUSÃO}

Espera-se com esta pesquisa não se esgote por aqui e que outras pessoas interessadas pelo estudo desse segmento populacional possam dar continuidade à discussão dessa temática. Essa pesquisa finaliza-se com o desejo de que possa contribuir da melhor forma possível para a produção do conhecimento na área $d a$ enfermagem gerontológica e que venha melhorar o cotidiano das pessoas que vivem a terceira idade.

\section{REFERÊNCIAS}

1. Almeida DT, Leitão GCM, Silva LF. Práticas terapêuticas em idosas com osteoporose: um campo para a educação em saúde. Texto Context Enferm 2003; 2 (02):174-181.

2. Prefeitura Municipal de Sobral (Brasil). Caderneta do Envelhecimento Saudável. Sobral: Prefeitura Municipal de Sobral; 2002.

3. Secretaria de Saúde (Brasil). Saúde Reprodutiva e sexual: um manual para a atenção primária e secundária (nível ambulatorial). 2.ed. Fortaleza: SESA; 2002.

4. Lima MJ . A Mulher acometida de acidente vascular cerebral: cuidados de enfermagem no processo de reabilitação.

Fortaleza.Dissertação[Mestrado em enfermagem clínico-Cirúrgica] - Universidade Federal do Ceará; 2003.

5. Zagonel IPS. Epistemologia do cuidado humano: arte e ciência da enfermagem abstraída das idéias de Watson. Text e Context Enferm 1996;5(1): 64-81.

6. Alves M. Como escrever teses e monografias: um roteiro passo a passo. Rio de Janeiro: Campus; 2003.

7. Leopardi MT. Metodologia da pesquisa na saúde. Santa Maria: Pellotti; 2001.

8. Moreira RVO, Barreto JAE. A outra Margem: filosofia, teorias de enfermagem e cuidado humano. Fortaleza: Casa José de Alencar ; 2001.

9. Watson J . A Mulher acometida de acidente vascular cerebral: cuidados de enfermagem no processo de reabilitação. Dissertação [Mestrado em enfermagem clínico-cirurgica] Universidade Federal do Ceará; 2003.

10. Sarter B . A Mulher acometida de Acidente Vascular Cerebral: cuidados de enfermagem no processo de reabilitação. Fortaleza .Dissertação [ Mestrado em Enfermagem clínico-Cirurgica] - Universidade Federal do Ceará; 2003. 
11. Mendes VO . Repercussões da Hanseníase no Cotidiano de Pessoas e de seus familiares. Sobral. Monografia[Especialização Residência em Saúde da Família]-Universidade Estadual Vale do Acaraú; 2003.

12. Haack AW. O Teste das oito cores de Lüscher. Rio de Janeiro: Renes; 1969.

13. Polit DF, Hungler BP. Fundamentos da pesquisa em enfermagem. 3.ed. Porto Alegre: Artes Médicas; 1995.

14. Watson J. Nursing: the philosophy and science of caring. Boston: Little; 1979.

15. Conselho Nacional de Saúde(Brasil). Resolução n 196 de, 15 nov 1996. Estabelece critérios sobre pesquisa envolvendo seres humanos. ; Diário Oficial da união 17 abr 1997.

16. Muraro RM, Boff L. Feminino e masculino: uma nova consciência para o encontro das diferenças. Rio de Janeiro: Sextante; 2002.
17. Vitiello N. O exercício da sexualidade. Atualidade em Geriatria 1997; 10(2).

18. Galvão L, Díaz J. Saúde sexual e reprodutiva no Brasil: dilemas e desafios. São Paulo: Hucitec; 1999. p.180-197.

19. Zago AV, Silva AS. Dançando com a terceira idade. A Terceira Idade 2003; 14 (28): 44-53.

20. Neri AL, Freire SA. E por falar em boa velhice. Campinas: Papirus; 2000.

21. Sociedade Brasileira de Geriatria e Gerontologia. Caminhos do Envelhecer. Rio de Janeiro: Revinter; 1994.

22. Buttler RN, Lewis MI. Sexo e amor na terceira idade. A Terceira Idade 2003; 14(28)

23. Heilborn ML. Sexualidade: o olhar das ciências sociais. Rio de Janeiro: Jorge Zahar Editor ;1999. p. 40 . 